\title{
Identifying The Functions of Two Biomarkers in Human Oligodendrocyte Progenitor Cell Development
}

\section{Haipeng zhou}

Southern Medical University https://orcid.org/0000-0002-2240-5362

\section{Ying He}

Southern Medical University

\section{Yinxiang Yang}

Sixth Medical Center of PLA General Hospital

\section{Zhaoyan Wang}

Sixth Medical Center of PLA General Hospital

\section{Qian Wang}

Sixth Medical Center of PLA General Hospital

\section{Caiyan Hu}

Sixth Medical Center of PLA General Hospital

\section{Xiaohua Wang}

Affiliated Hospital of Nantong University

Siliang Lu

Guangxi Medical University

Ke Li

Guangxi Medical University

Zuo Luan ( $D$ luanzuo@aliyun.com )

Southern Medical University

\section{Research}

Keywords: cell sorting, gene ontology enrichment analysis, human oligodendrocyte progenitor cells, NG2, A2B5

Posted Date: November 13th, 2020

DOl: https://doi.org/10.21203/rs.3.rs-104756/v1

License: (c) (1) This work is licensed under a Creative Commons Attribution 4.0 International License. 
Version of Record: A version of this preprint was published at Journal of Translational Medicine on May 1st, 2021. See the published version at https://doi.org/10.1186/s12967-021-02857-8. 
Identifying the functions of two biomarkers in human oligodendrocyte progenitor cell development

Haipeng zhou ${ }^{1,2}$, Ying $\mathrm{He}^{1,2}$, Yinxiang Yang ${ }^{2,5}$, Zhaoyan Wang ${ }^{2}$, Qian Wang ${ }^{2}$, Caiyan $\mathrm{Hu}^{2}$, Xiaohua Wang ${ }^{1,4}$, Siliang $\mathrm{Lu}^{2,3}, \mathrm{Ke} \mathrm{Li}^{2,3}$, Zuo Luan ${ }^{1,2,3^{*}}$

${ }^{1}$ Second Clinical College, Southern Medical University, Guangzhou 510515, China

${ }^{2}$ Laboratory of Pediatrics, The Sixth Medical Center of PLA General Hospital, Beijing 100048, China

${ }^{3}$ The first Clinical Medical College, Guangxi Medical University, Nanning, Guangxi 530021, China

${ }^{4}$ Affiliated Hospital of Nantong University, Nantong 226001, China

${ }^{5}$ Stem Cell and Regenerative Medicine Laboratory, Beijing Institute of Transfusion Medicine, Beijing 100850, China

${ }^{*}$ Corresponding author:

Fax: +861066958303 .

E-mail address: luanzuo@aliyun.com (Zuo Luan). 


\section{Abstract}

Background: Myelin oligodendrocytes develop from migratory and proliferative human oligodendrocyte progenitor cells (hOPCs), which express typical marker proteins and lipids. It is well known that NG2 and A2B5 are important biological markers of hOPCs. Yet, the differences in myelination ability between the two cell lineages have not been studied in depth. The sequence of expression of NG2 and A2B5 during the development of hOPCs is also controversial.

Methods: Using cell sorting technology, we obtained a large number of sterile, high-purity NG2+/-, A2B5+/- cells with high viability. Further research was then conducted via in vitro cell proliferation and migration assays, single-cell sequencing, mRNA sequencing, and cell transplantation into shiverer mice.

Results: The results showed that the ability of cell migration and proliferation of the four groups of cells from high to low was: A2B5->NG2->NG2+>A2B5+. The ability for oligodendrocyte differentiation from high to low was: $\mathrm{NG} 2->\mathrm{A} 2 \mathrm{~B} 5->\mathrm{A} 2 \mathrm{~B} 5+>\mathrm{NG} 2+$.

Conclusion : The results of this study suggest that the migration ability of the cells was inversely proportional to their myelination ability. NG2 may be a marker of early oligodendrocyte progenitor cells, and is conducive to cell migration and proliferation, while A2B5 may be a marker of slightly mature oligodendrocyte progenitor cells and is conducive to cell differentiation. The migration, proliferation, and myelination capacities of the negative cell population were stronger than those of the positive cell population. In summary, these results suggest that oligodendrocyte progenitor cells in the mid-stage may be most suitable for clinical cell transplantation to treat demyelinating diseases.

Keywords: cell sorting/ gene ontology enrichment analysis/ human oligodendrocyte progenitor cells/ NG2/ A2B5 


\section{Background}

Current clinical methods for the treatment of demyelinating disease, in addition to more mature immunotherapy, focus on cell transplantation therapies. Cell transplantation is a strategy aimed at treating this disease by replacing the lost or damaged cell population [1]. The transplanted cell types consist mainly of human oligodendrocyte progenitor cells (hOPCs) and mature human oligodendrocytes (OLs). These cells may be obtained directly from foetal and adult brain tissues [2-4] or through induced embryonic stem cells (ESCs) $[5,6]$ or induced pluripotent stem cells (iPSCs) [7, 8]. Although many types of cells can be transplanted, their effects on the repair or regeneration of myelin post transplantation are variable, and these effects may be associated with the different states of the transplanted cells. Therefore, it is necessary to select a cell population that is most conducive to myelin regeneration after transplantation.

Myelin oligodendrocytes are key cells for myelin formation. They are derived from migratory and proliferative hOPCs. Therefore, hOPCs are a potential option for cell transplantation for the treatment of demyelinating diseases. In addition to platelet derived growth factor receptor alpha (PDGFR- $\alpha$ ), which is a marker of hOPCs, chondroitin sulphate proteoglycan 4 (NG2) and ST8 alpha-N-acetyl-neuraminide alpha-2,8-sialyltransferase 1 (A2B5) are two important, generally recognised markers [9-11]. Although studies have shown that both NG2-positive (NG2+) and A2B5-positive (A2B5+) cells have the ability to differentiate into oligodendrocytes in vivo and in vitro $[12,13]$, the differences in myelination ability between the two cell lineages have not been studied in depth. The sequence of expression of NG2 and A2B5 during the development of hOPCs is also controversial. Nishiyama et al. hypothesised that the expression of NG2 occurs slightly later than that of A2B5 [14, 15], while Baracskay et al. suggested that NG2+ cells appear before the expression of A2B5+ cells. Other studies have shown that as hOPCs differentiate into mature oligodendrocytes, both of these markers are downregulated [16]. This dynamic change in expression may imply that these two markers play different roles at 
different stages in the development of hOPCs. Therefore, elucidating the functional differences and mutual relationship between the two markers at different stages of hOPC development was the main purpose of our research.

In preliminary research, we cultured extracted human foetal brain neural stem cells (NSCs) in vitro and successfully induced their differentiation into hOPCs [17]. Due to the fragile nature of hOPCs, MACSQuant ${ }^{\circledR}$ Tyto ${ }^{\circledR}$ (Miltenyi Biotec, Bergisch-Gladbach, Germany) was chosen for cell sorting. This new sorting method can yield a large number of high-purity, high-activity target cells and also meet the gel microdroplet (GMD) levels required for clinical cell preparation, facilitating future clinical applications (www.miltenyibiotec.com/local).

After obtaining the target cells, we studied the gene expression levels of these four groups of cells and the functions of the cells in vivo and in vitro. Single cell RNA sequencing (scRNA-seq) can be used to study the different subgroups of hOPCs before sorting $[18,19]$, while RNA sequencing (RNA-seq) can be used to perform overall differential gene expression analysis and functional enrichment analysis on the sorted cell population $[20,21]$. In vivo and in vitro cell function is assessed mainly through in vitro proliferation [22] and migration experiments [23] as well as the evaluation of the myelinating ability of the sorted cells transplanted into the shiverer mouse corpus callosum [24, 25].

In this study we investigated the differences in the proliferation, migration, and myelination ability of $\mathrm{NG} 2+/-$ and $\mathrm{A} 2 \mathrm{~B} 5+/-$ cells during the development of hOPCs, and found that the migration ability of hOPCs may be inversely proportional to their myelination ability. This finding provides a theoretical basis for the sequence of expression of NG2 and A2B5 during the development of hOPCs. The results of this study provide insights into the selection of cell types for cell transplantation to treat demyelinating diseases.

\section{Methods}

\section{Cultivation and identification of hOPCs}


hOPCs were prepared in the Pediatric Laboratory of the Sixth Medical Centre of PLA General Hospital, China, using previously established methods of cultivation and identification. Briefly, hOPCs were induced by NSCs. The cells were cultured in a self-made medium at $37{ }^{\circ} \mathrm{C}$ in a humidified $5 \% \mathrm{CO}_{2}$ incubator. The hOPCs were identified using immunofluorescence staining. Monoclonal mouse anti-PDGFR- $\alpha$ (1:250, Cat. \#C2318, CST, Boston, Massachusetts, USA), mouse anti-A2B5 (1:50, Cat. \# MAB1416, R\&D Systems, Minneapolis, Minnesota, USA), and rabbit anti-NG2 (1:50, Cat. \# ab83178, Abcam, Cambridge, Cambridgeshire, UK) antibodies were used to identify hOPCs. Cell nuclei were stained with 4',6-diamidino-2-phenylindole (DAPI) (1:20, Cat. \# 28718-90-3, Sigma-Aldrich, St. Louis, Missouri, USA) for $5 \mathrm{~min}$ and then observed using fluorescence microscopy (IX-70, Olympus Corporation, Tokyo, Japan).

\section{Single-cell RNA sequencing (scRNA-seq) of hOPCs}

To evaluate the gene expression of these three biomarkers, scRNA-seq was performed at the Beijing Novogene Bioinformatics Technology Co (Beijing, China). We prepared a cell suspension containing a total number of cells greater than $1 \times 10^{6}$. The prepared cell suspension was quickly loaded into the chromium microfluidic chip with 3 ' chemistry, and a barcode of 10x Chromium Controller was attached. The cells were then subjected to RNA reverse transcription. A sequencing library was constructed using reagents from the Chromium Single Cell 3'v2 kit (10x Genomics, Pleasanton, California), according to the manufacturer's instructions. Illumina was used for sequencing, according to the manufacturer's instructions (Illumina, San Diego, California). 
For the analysis of PDGFR- $\alpha$, A2B5, and NG2 expression in hOPCs, the cells were digested and washed once with buffer ( $\mathrm{pH}$ 7.2 PBS, 0.5\% BSA) and centrifuged at $500 \times g$ for $5 \mathrm{~min}$ at $4^{\circ} \mathrm{C}$. Fragment crystallisable $(\mathrm{Fc})$ receptors were blocked with normal mouse serum for $10 \mathrm{~min}$ at $25^{\circ} \mathrm{C}$. The cells were surface-stained with PDGFR- $\alpha$ BV421 mouse anti-human (Cat. \#562799, BD Biosciences, Franklin Lake, New Jersey, USA), A2B5 PE mouse anti-human (Cat. \#130-093-581, Miltenyi Biotec, Bergisch-Gladbach, Germany), or NG2 APC mouse anti-human (Cat. \#FAB2585A, R\&D Systems, Minnesota, USA) antibodies for $30 \mathrm{~min}$ at $4^{\circ} \mathrm{C}$. After surface staining, hOPCs were washed once with the abovementioned buffer and centrifuged at $500 \times g$ for $5 \mathrm{~min}$ at $4^{\circ} \mathrm{C}$. The cell pellet obtained was resuspended in the same buffer for flow cytometry analysis and cell sorting.

\section{FlowSight image flow cytometric analysis}

Cells were acquired using a FlowSight ${ }^{\circledR}$ imaging flow cytometer (Amnis ${ }^{\circledR}$, part of EMD Millipore, Massachusetts, USA). Cell debris and dead cells were identified using the aspect ratio and area of the cells, and removed. Approximately 7000 cells were obtained during each analysis. Channel 7 was used to detect BV421, Channel 3 to acquire PE, and Channel 11 to detect APC. Single colour control samples were compensated using a compensation matrix (.rif) and converted to data analysis files (.daf) and compensated image files (.cif) using the same settings. The data were analysed using Ideas software, version 6.2.

\section{MACSQuant ${ }^{\circledR}$ Tyto ${ }^{\circledR}$ cell sorting}

The fluorescent antibody-labelled cells were transferred into a MACSQuant ${ }^{\circledR}$ Tyto $\AA$ Cartridge. The input sample contained $5 \times 10^{6}$ hOPCs in $10 \mathrm{~mL}$ MACSQuant Tyto Running Buffer. Logical gating hierarchies were constructed using MACSQuant Tyto software before sorting. Cell debris, doublets, and dead cells were gated out, and a gate was set on the target cells. The sample was sorted at $4 \mathrm{~mL} / \mathrm{h}$ using approximately 
140 mbar pressure. Upon completion of sorting, non-sorted samples were analysed using a FlowSight ${ }^{\circledR}$ imaging flow cytometer to assess cell purity and yield.

\section{RNA-seq analysis}

Total RNA was isolated from the four sorted populations using RNAiso Plus (Takara Bio). RNA-seq was performed at the Beijing Novogene Bioinformatics Technology Co, using the Illumina NovaSeq platform. RNA Nano 6000 Assay Kits and the Bioanalyzer 2100 system (Agilent Technologies, California, USA) were used to evaluate RNA integrity. A NanoPhotometer ${ }^{\circledR}$ spectrophotometer (IMPLEN, California, USA) was used to check the purity of the RNA. Clustering and sequencing (Novogene Experimental Department) were conducted according to the manufacturer's instructions. The index-coded samples were clustered using a cBot Cluster Generation System and TruSeq PE Cluster Kit v3-cBot-HS (Illumina). Finally, the libraries were sequenced using the Illumina NovaSeq platform and 150bp paired-end reads were generated.

\section{Differential expression analysis and gene ontology (GO) enrichment analysis}

We used the edgeR package for the $\mathrm{R}$ statistical software with one scaling normalization factor to adjust each sequenced library for read counts, and then performed differential gene expression analysis. The $\mathrm{p}$ values were adjusted using the Hochberg and Benjamini method. Differentially expressed genes were analysed for GO enrichment by the clusterProfiler $\mathrm{R}$ software package, and the bias in gene expression was corrected. GO terms included were as follows: biological process (BP), cellular component (CC), and molecular function (MF). When the corrected $p$ value was $<0.05$, differentially expressed genes were considered to be significantly enriched in the GO terms.

\section{Cell migration assays}


Cell migration was measured in Transwell filters with 8-mm pores (Corning, Tewksbury, Massachusetts, USA). Inserts were coated with human fibronectin protein (Cat. \#33016015, Thermo Fisher Scientific, Waltham, Massachusetts, USA). Sorted cells $\left(2 \times 10^{4}\right.$ cells $)$, in $200 \mu \mathrm{L}$ of medium, were loaded into the upper chambers, and $500 \mu \mathrm{L}$ of the hOPC medium was added to the chamber. After incubation for $18 \mathrm{~h}$ at $37^{\circ} \mathrm{C}$, a cotton swab was used to wipe the cells that had not migrated onto the upper surface of the chamber. The migrated cells were fixed with $4 \%$ paraformaldehyde and stained with DAPI (1:20). Images were acquired using a fluorescence microscope. The migrated cells were quantified using ImageJ software[26] by analysing cell nuclei from at least five randomly selected fields per chamber. The cell migration rate was calculated as follows: cell migration rate $(\mathrm{V} 1 \%)=\mathrm{N} 1 / \mathrm{N} 2 \times 100 \%$, where $N 1$ refers to the initial cell seeding number, and N2 refers to the number of migrated cells. The experiment was repeated three times independently in the laboratory.

\section{Cell proliferation assays}

The proliferation of different cell populations was evaluated using cell counting kit- 8 (CCK-8) assays (Cat. \#CK04, Dojindo, Kumamoto, Japan). hOPCs (6000 cells/well) were seeded into 96 -well plates and cultured for $24 \mathrm{~h}$ at $37^{\circ} \mathrm{C}$ and $5 \% \mathrm{CO}_{2}$. The same volume of hOPC medium was added to the blank control group, and six parallel wells were set for each group without any cells. At different experimental time points $(1,3$, $5,7,9$, and 11 days), $10 \mu \mathrm{L}$ of CCK-8 solution was added to the wells and incubated at $37^{\circ} \mathrm{C}$ for $2 \mathrm{~h}$. Six wells were set for each experiment at each time point. The absorbance at $450 \mathrm{~nm}$ was measured with a microplate reader (BioTek, Winooski, Vermont, USA). At least three experiments were performed, and each was tested in triplicate. The experiment was repeated three times independently in the laboratory [27].

\section{Cell transplantation in shiverer mice}


Homozygous shiverer mice (The Jackson Laboratory, Bar Harbor, Maine, USA) were maintained at the Sixth Medical Centre of PLA General Hospital in a specific pathogen-free environment. All animal experiments were performed according to protocols approved by the Sixth Medical Centre of PLA General Hospital Animal Care and Use Committee (Application No. SCXK-2012-0001). New-born pups were transplanted within a day after birth. Different cell populations $\left(1 \times 10^{5} / 1.5 \mu \mathrm{L}\right)$ were injected bilaterally into the corpus callosum using a mouse brain stereotaxic apparatus (Stoelting, Chicago, Illinois, USA). Untransplanted homozygous shiverer mice $(n=6)$ were selected at random as the control group. The postoperative pups were returned to their mother and were weighed every day. After weaning, each mouse was reared separately. At three months of age, the mice were anaesthetised with $1 \%$ pentobarbital sodium. Mouse brain samples were perfused with PBS, and fixed with 4\% paraformaldehyde (Cat. \#MFCD00133991, Thermo Fisher Scientific, Waltham, USA).

\section{Transmission electron microscopy (TEM)}

After the corpus callosum was separated, it was immediately fixed in $2.5 \%$ glutaraldehyde at $4^{\circ} \mathrm{C}$, and then fixed with $1 \%$ osmic acid for $2 \mathrm{~h}$. After embedding in epoxy resin, tissue samples were sliced into ultrathin sections using a PowerTome $\mathrm{X}$ Ultramicrotome (RMC products by Boeckeler, Tucson, Arizona, USA). The samples were then stained with uranyl acetate and lead citrate, following which the structure of myelin was observed using TEM (H7650-B, HITACHI, Tokyo, Japan). A field of view was randomly selected for each mouse, and the number of myelin sheaths in the photo was counted. Finally, the remyelination rate and G-ratio were calculated.

\section{Tissue immunofluorescence staining}

The mouse brain samples were fixed in $4 \%$ formaldehyde overnight and immersed in 
$25 \%$ sucrose solution for three days. Serial frozen sections $(5-\mu \mathrm{m}$ thick) were obtained after embedding at optimal cutting temperature. Myelination was identified using immunohistochemical staining. Cryosections were rewarmed at $37^{\circ} \mathrm{C}$ for $1 \mathrm{~h}$ and then rehydrated in $0.03 \%$ Triton $\mathrm{X}-100$ in PBS for 45 min. Blocking was performed in 3\% normal goat serum (Cat. \#G9023, Sigma-Aldrich, St. Louis, USA) for $45 \mathrm{~min}$. The rat anti-myelin basic protein (MBP) (Cat. \#Ab7349, Abcam, Cambridge, UK) antibody was diluted in blocking solution at 1:200 and incubated overnight at $4^{\circ} \mathrm{C}$. After washing with PBS the following day, the brain tissue was incubated with the secondary antibody (Alexa Fluor ${ }^{\circledR} 488$ donkey anti-rat $\operatorname{IgG}, 1: 500$, Cat. \#Ab150153, Abcam, Cambridge, UK) in a dark room for $1.5 \mathrm{~h}$, and then washed with PBS. A fluorescence microscope (IX-70, Olympus Corporation) was used to observe the fluorescently labelled samples, and the mean optical density of MBP was analysed using Image Pro Plus 6.0 (Media Cybernetics).

\section{Statistical analysis}

The experimental data in this study were analysed using GraphPad Prism version 8 software (GraphPad Software, San Diego, California USA, www.graphpad.com) and SPSS version 22.0. Differences were considered to be statistically significant at $\mathrm{p}<0.05$. Statistical significance was determined using independent samples Student's t-tests or one-way ANOVA followed by Bonferroni tests. All experimental data are expressed as mean $\pm \mathrm{SD}$.

\section{Results}

\section{hOPC identification and biomarker detection}

We identified hOPCs using cell morphology and immunofluorescence staining. hOPCs had a typical bipolar, bead-like appearance, and expressed PDGFR- $\alpha$, NG2, 
and A2B5 (Fig 1A). Based on the results of flow cytometry analysis, the proportion of PDGFR- $\alpha+$ cells was $74.13 \pm 1.74 \%$ of the whole cell population; A2B5+ cells made up 25.97 $\pm 0.74 \%$; and NG2+ cells comprised $14.41 \pm 0.81 \%$ (Fig 1B). Volume uniformity of hOPCs, which had a cell diameter $<20 \mu \mathrm{m}$, and the expression of the three cell markers on a single cell membrane were observed (Fig 1C). scRNA-seq showed that the proportions of PDGFR- $\alpha+, \mathrm{NG} 2+$, and A2B5+ cells in hOPCs were $67 \%(n=5309), 13 \%(n=1002)$, and 16\% $(n=1243)$, respectively (Fig 1D).

\section{hOPC sorting and RNA-seq}

To obtain NG2+/- and A2B5+/- cells, we performed cell sorting on hOPCs. After sorting, the viability of the sorted cells was above $98 \%$. In the negative group, the proportion of A2B5+ cells dropped from 28.1 to $4.03 \%$, and the proportion of NG2+ cells decreased from 8.22 to $1.01 \%$. NG2+ and A2B5+ cells were almost completely absent in the NG2- and A2B5- cell populations (Fig S1).

In order to study the differential gene expression of the four groups, we performed RNA-seq. The results showed that, compared with A2B5+ cells, NG2+ cells had 1737 upregulated and 1225 downregulated genes. Compared with A2B5cells, A2B5+ cells had 633 upregulated and 333 downregulated genes. Compared with A2B5+ cells, NG2- cells had 1381 upregulated and 834 downregulated genes. Compared with A2B5- cells, NG2- cells had 967 upregulated and 669 downregulated genes. Compared with NG2- cells, NG2+ cells had 466 upregulated and 352 downregulated genes. Compared with NG2+ cells, A2B5- cells had 1126 upregulated and 1400 downregulated genes (Fig 2A). Fig 2B shows a heat map of the genes which were differentially expressed among the four cell populations.

We then performed $\mathrm{GO}$ enrichment analysis on the upregulated and downregulated genes in each group. Fig 3A shows the key GO terms. BP mainly included cell proliferation (GO:0050673), migration (GO:0050673), oligodendrocyte differentiation (GO:0048709), and myelination (GO:0042552); CC mainly included extracellular matrix (GO:0031012) and axon part (GO:0033267); MF included 
actin-binding (GO:0003779). Bubble plots showed that in NG2+ and A2B5+ cells, the upregulated genes were mainly involved in cell migration and proliferation, while the downregulated genes were mainly involved in oligodendrocyte differentiation (Fig 3B). The results of the other groups are provided in Fig S2. In terms of cell migration and proliferation, the gene enrichment of the four groups of cells from high to low was A2B5->NG2->NG2+>A2B5+. The gene enrichment intensity for oligodendrocyte differentiation from high to low was NG2->A2B5->A2B5+>NG2+.

\section{Evaluation of the migration and proliferation function of hOPCs in vitro}

We used Transwell assays to evaluate the migration of the cells. After the cells had migrated for $18 \mathrm{~h}$, the nuclei were stained with DAPI (Fig 4A). The migration rates of the $\mathrm{NG} 2+$ and $\mathrm{A} 2 \mathrm{~B} 5+$ cell populations were $7.89 \pm 0.75 \%$ and $4.41 \pm 0.38 \%$, respectively. The migration rates of the NG2- and A2B5- cell populations were $10.04 \pm 0.18 \%$ and $14.82 \pm 0.48 \%$, respectively. Statistical analysis showed that the migration of $\mathrm{NG} 2+$ was stronger than that of $\mathrm{A} 2 \mathrm{~B} 5+(*, \mathrm{p}=0.0278)$ and that the migration of NG2- was weaker than that of A2B5- $(*, p=0.0267)$. The migration of $\mathrm{A} 2 \mathrm{~B} 5+$ was weaker than that of A2B5- $\left.{ }^{*}, \mathrm{p}=0.0240\right)$, and the migration of $\mathrm{NG} 2+$ was weaker than that of NG2- $(* *, p=0.0017)$ (Fig 4B). The proliferation assay results showed that the proliferation of $\mathrm{NG} 2+$ was stronger than that of $\mathrm{A} 2 \mathrm{~B} 5+(* *$, $\mathrm{p}=0.0015)$, while the proliferation of NG2- was weaker than that of A2B5- (**, $\mathrm{p}=0.0028)$. The proliferation of $\mathrm{A} 2 \mathrm{~B} 5-$ was stronger than that of $\mathrm{A} 2 \mathrm{~B} 5+(* *$, $\mathrm{p}=0.0027)$, and the proliferation of $\mathrm{NG} 2+$ was weaker than that of NG2- $(* *$, $\mathrm{p}=0.0079)($ Fig 4C).

\section{hOPCs were transplanted into the corpus callosum of shiverer mice}

We evaluated the myelinating ability of these four groups of cells in vivo. TEM showed that the myelin sheath of homozygous shiverer mice did not form major dense lines or myelin compaction (Fig S3). In shiverer mice transplanted with positive cells, 
although there was a small amount of myelin formation, most of the myelin sheaths were immature, the structure of the myelin was loose, and there was no compacted dense line. In shiverer mice transplanted with negative cells, the myelin sheaths were highly mature and had compacted dense lines (Fig 5A). The myelination rate analysis and G-ratio analysis of the four groups of cells showed that the NG2- cell group exhibited the strongest myelination effect, while NG2+ cells had the least effect $(* \sim * * *$, Fig 5B, C). Finally, MBP immunofluorescence staining was performed on shiverer mouse brain tissue to further confirm myelination (Fig 5A).

\section{Discussion}

Both A2B5+ and NG2+ cells can differentiate into oligodendrocytes in vivo and in vitro $[28,29]$ and can form myelin structures in brain tissue, consistent with our experimental results. Other studies on the two cell populations also compared their myelinating ability. According to some reports, A2B5+ cells have greater capacity to ensheath nanofibers, and NG2+ cells fail to differentiate into oligodendrocytes as quickly as A2B5+ cells [30]. Our in vivo experiments also showed that the myelinating effect of $\mathrm{NG} 2+$ cells is not as notable as that of A2B5+ cells. The reason for this phenomenon may be that NG2+ cells are multifunctional cells with lineage plasticity, and NG2+ cells contain heterogeneous progenitor cells with different differentiation potentials [31]. Because transplanted NG2+ cells migrate extensively in the brain and differentiate into oligodendrocytes, astrocytes, and even neurons, the rates and effects of myelination of NG2+ cells are inferior to those observed for A2B5+ cells after cell transplantation.

We found that NG2- cells showed the strongest myelinating ability, while NG2+ cells showed the weakest myelinating ability. A2B5- cells showed the strongest proliferation and migration, while A2B5+ cells showed the weakest proliferation and migration. Therefore, we concluded that the migration, proliferation, and myelinating ability of the negative cell populations is stronger than that of the positive cell 
populations. We speculate that the reason for this may be that negative cells contain more cell types that exhibit more comprehensive and powerful functions.

In addition to the above studies on proliferation, migration, and myelination, there is still controversy about the order of the expression of the two markers. Some studies have shown that during development $\mathrm{NG} 2+$ cells originate from the subventricular region and appear prior to A2B5+ cells [32-34]. Other studies have shown that A2B5 is the first glial marker to appear and is expressed on both neurons and glial cells in vivo [35]. Some studies have found that the myelinating ability of OLs gradually increases during their development, while their migration ability gradually decreases [36]. A similar observation was made in our research regarding $\mathrm{NG} 2+$ cells and A2B5+ cells, in which myelination ability was inversely proportional to migration ability. This result indicates that NG2 represents early hOPCs with strong migration ability, while A2B5 represents slightly more mature hOPCs with strong differentiation potential. Therefore, our results support the hypothesis that the expression of NG2 on cells occurs earlier than the expression of A2B5.

\section{Conclusion}

In summary, we used cell sorting to sort self-made hOPCs and obtained a large number of sterile, high-purity $\mathrm{NG} 2+/-$ and $\mathrm{A} 2 \mathrm{~B} 5+/-$ cells with high viability. The feasibility of using this technology to sort relatively fragile cells was verified in this study, and establishes the value of a new sorting technology for future clinical cell transplantation processes. Through genetic testing and cell function research, we clarified that the migration, proliferation, and myelination of a single cell population is weaker than that of a mixed cell population, and that cell migration is inversely proportional to myelination ability. By comparing the differences between the functions of NG2+/- and A2B5+/- cells during the development of hOPCs into OLs, we propose that hOPCs in the middle developmental stages may be most suitable for cell transplantation. 


\begin{abstract}
Abbreviations
A2B5: ST8 alpha-N-acetyl-neuraminide alpha-2,8-sialyltransferase 1; ANOVA: analysis of variance; BP: Biological process; CCK-8: cell counting kit-8; ECM: extracellular matrix; GO: Gene Ontology; hOPCs: human oligodendrocyte progenitor cells; GMD: ; OLs: human oligodendrocytes; MBP: myelin basic protein; NSCs: neural stem cells; NG2: chondroitin sulfate proteoglycan 4; PDGFR- $\alpha$ : platelet derived growth factor receptor alpha; RNA-Seq: RNA sequencing; scRNA-seq: Single cell RNA sequencing; TEM: Transmission electron microscopy
\end{abstract}

Ethics approval and consent to participate: Not applicable.

Consent for publication: Not applicable.

\title{
Availability of data and materials
}

All data generated or analysed during this study are included in this published article. All of the raw data for this study will be forthcoming.

\section{Competing interests}

The authors report no conflicts of interest in this work.

\section{Funding}

This research was supported by the National Key R\&D Program of China (NO.2017YFA0104200).

\section{Authors' contributions}

HPZ, YXY, and ZL designed the experiments. HPZ, YH, YXY, ZYW, QW, CYH, XHW, SLL, KL, and ZL performed the experiments. HPZ, YH, and YXY analysed the data. ZYW, QW, CYH, XHW, SLL, KL, and ZL contributed materials/reagents/analysis tools. HPZ wrote the manuscript. 


\section{Acknowledgements}

The authors appreciate the technical support and other help from Leping Zhang, Jing Zang, Chang Liu, and Qian Guan. We would like to thank Editage (www.editage.cn) for English language editing.

\section{References:}

1. Alexanian AR, Svendsen CN, Crowe MJ, Kurpad SN. Transplantation of human glial-restricted neural precursors into injured spinal cord promotes functional and sensory recovery without causing allodynia. CYTOTHERAPY. 2011 2011-01-01;13(1):61-8.

2. Dietrich J, Noble M, Mayer-Proschel M. Characterization of A2B5+ glial precursor cells from cryopreserved human fetal brain progenitor cells. GLIA. 2002 2002-10-01;40(1):65-77.

3. Roy NS, Wang S, Harrison-Restelli C, Benraiss A, Fraser RA, Gravel M, et al. Identification, isolation, and promoter-defined separation of mitotic oligodendrocyte progenitor cells from the adult human subcortical white matter. J NEUROSCI. 1999 1999-11-15;19(22):9986-95.

4. Windrem MS, Nunes MC, Rashbaum WK, Schwartz TH, Goodman RA, McKhann GN, et al. Fetal and adult human oligodendrocyte progenitor cell isolates myelinate the congenitally dysmyelinated brain. NAT MED. 2004 2004-01-01;10(1):93-7.

5. Izrael M, Zhang P, Kaufman R, Shinder V, Ella R, Amit M, et al. Human oligodendrocytes derived from embryonic stem cells: Effect of noggin on phenotypic differentiation in vitro and on myelination in vivo. MOL CELL NEUROSCI. 2007 2007-03-01;34(3):310-23.

6. Keirstead HS, Nistor G, Bernal G, Totoiu M, Cloutier F, Sharp K, et al. Human embryonic stem cell-derived oligodendrocyte progenitor cell transplants remyelinate and restore locomotion after spinal cord injury. J NEUROSCI. 2005 2005-05-11;25(19):4694-705.

7. Douvaras P, Wang J, Zimmer M, Hanchuk S, O'Bara MA, Sadiq S, et al. Efficient generation of myelinating oligodendrocytes from primary progressive multiple sclerosis patients by induced pluripotent stem cells. STEM CELL REP. 2014 2014-08-12;3(2):250-9.

8. Wang S, Bates J, Li X, Schanz S, Chandler-Militello D, Levine C, et al. Human iPSC-derived oligodendrocyte progenitor cells can myelinate and rescue a mouse model of congenital hypomyelination. CELL STEM CELL. 2013 2013-02-07;12(2):252-64. 
9. Hart IK, Richardson WD, Bolsover SR, Raff MC. PDGF and intracellular signaling in the timing of oligodendrocyte differentiation. J CELL BIOL. 1989 1989-12-01;109(6 Pt 2):3411-7.

10. Wolswijk G, Noble M. Identification of an adult-specific glial progenitor cell. DEVELOPMENT. 1989 1989-02-01;105(2):387-400.

11. Roy NS, Wang S, Harrison-Restelli C, Benraiss A, Fraser RA, Gravel M, et al. Identification, isolation, and promoter-defined separation of mitotic oligodendrocyte progenitor cells from the adult human subcortical white matter. J NEUROSCI. 1999 1999-11-15;19(22):9986-95.

12. Lyu Q, Zhang ZB, Fu SJ, Xiong LL, Liu J, Wang TH. Microarray Expression Profile of lncRNAs and mRNAs in Rats with Traumatic Brain Injury after A2B5+ Cell Transplantation. CELL TRANSPLANT. 2017 2017-10-01;26(10):1622-35.

13. Baracskay KL, Kidd GJ, Miller RH, Trapp BD. NG2-positive cells generate A2B5-positive oligodendrocyte precursor cells. GLIA. 2007 2007-08-01;55(10):1001-10.

14. Nishiyama A, Komitova M, Suzuki R, Zhu X. Polydendrocytes (NG2 cells): multifunctional cells with lineage plasticity. NAT REV NEUROSCI. 2009 2009-01-01;10(1):9-22.

15. Huang W, Bai X, Meyer E, Scheller A. Acute brain injuries trigger microglia as an additional source of the proteoglycan NG2. Acta Neuropathol Commun. 2020 2020-08-26;8(1):146.

16. Ju PJ, Liu R, Yang HJ, Xia YY, Feng ZW. Clonal analysis for elucidating the lineage potential of embryonic NG2+ cells. CYTOTHERAPY. 2012 2012-05-01;14(5):608-20.

17. Lu Y, Yang Y, Wang Z, Wang C, Du Q, Wang Q, et al. Isolation and culture of human oligodendrocyte precursor cells from neurospheres. BRAIN RES BULL. 2015 2015-09-01;118:17-24. 18. Paik DT, Tian L, Williams IM, Rhee S, Zhang H, Liu C, et al. Single-Cell RNA-seq Unveils Unique Transcriptomic Signatures of Organ-Specific Endothelial Cells. CIRCULATION. 2020 2020-09-15.

19. Feng B, Zhu J, Xu Y, Chen W, Sheng X, Feng X, et al. Immunosuppressive effects of mesenchymal stem cells on lung B cell gene expression in LPS-induced acute lung injury. STEM CELL RES THER. 2020 2020-09-25;11(1):418.

20. Liu T, Zhu B, Liu Y, Zhang X, Yin J, Li X, et al. Multi-omic comparison of Alzheimer's variants in human ESC-derived microglia reveals convergence at APOE. J EXP MED. 2020 2020-12-07;217(12).

21. Seong RK, Lee JK, Cho GJ, Kumar M, Shin OS. mRNA and miRNA profiling of Zika 
virus-infected human umbilical cord mesenchymal stem cells identifies miR-142-5p as an antiviral factor. Emerg Microbes Infect. 2020 2020-12-01;9(1):2061-75.

22. Wang J, Liu X, Qiu Y, Shi Y, Cai J, Wang B, et al. Cell adhesion-mediated mitochondria transfer contributes to mesenchymal stem cell-induced chemoresistance on $\mathrm{T}$ cell acute lymphoblastic leukemia cells. J HEMATOL ONCOL. 2018 2018-01-22;11(1):11.

23. Crippa S, Rossella V, Aprile A, Silvestri L, Rivis S, Scaramuzza S, et al. Bone marrow stromal cells from beta-thalassemia patients have impaired hematopoietic supportive capacity. J CLIN INVEST. 2019 2019-02-25;129(4):1566-80.

24. Uchida N, Chen K, Dohse M, Hansen KD, Dean J, Buser JR, et al. Human neural stem cells induce functional myelination in mice with severe dysmyelination. SCI TRANSL MED. 2012 2012-10-10;4(155):136r-155r.

25. Mitome M, Low HP, van den Pol A, Nunnari JJ, Wolf MK, Billings-Gagliardi S, et al. Towards the reconstruction of central nervous system white matter using neural precursor cells. BRAIN. 2001 2001-11-01;124(Pt 11):2147-61.

26. Schneider CA, Rasband WS, Eliceiri KW. NIH Image to ImageJ: 25 years of image analysis. NAT METHODS. 2012 2012-07-01;9(7):671-5.

27. Fu C, Zhou H, Wang Y, Liu D, Li J, Deng H, et al. One-pot synthesis of dextran-coated iron oxide nanoclusters for real-time regional lymph node mapping. Int J Nanomedicine. 2017 2017-01-20;12:3365-74.

28. Diers-Fenger M, Kirchhoff F, Kettenmann H, Levine JM, Trotter J. AN2/NG2 protein-expressing glial progenitor cells in the murine CNS: isolation, differentiation, and association with radial glia. GLIA. 2001 2001-05-01;34(3):213-28.

29. Stallcup WB. The NG2 antigen, a putative lineage marker: immunofluorescent localization in primary cultures of rat brain. DEV BIOL. 1981 1981-04-15;83(1):154-65.

30. Esmonde-White C, Yaqubi M, Bilodeau PA, Cui QL, Pernin F, Larochelle C, et al. Distinct Function-Related Molecular Profile of Adult Human A2B5-Positive Pre-Oligodendrocytes Versus Mature Oligodendrocytes. J Neuropathol Exp Neurol. 2019 2019-06-01;78(6):468-79.

31. Schonberg DL, Goldstein EZ, Sahinkaya FR, Wei P, Popovich PG, McTigue DM. Ferritin stimulates oligodendrocyte genesis in the adult spinal cord and can be transferred from macrophages to NG2 cells in vivo. J NEUROSCI. 2012 2012-04-18;32(16):5374-84. 
32. Mallon BS, Shick HE, Kidd GJ, Macklin WB. Proteolipid promoter activity distinguishes two populations of NG2-positive cells throughout neonatal cortical development. J NEUROSCI. 2002 2002-02-01;22(3):876-85.

33. Greenhalgh AD, David S, Bennett FC. Immune cell regulation of glia during CNS injury and disease. NAT REV NEUROSCI. 2020 2020-03-01;21(3):139-52.

34. Baracskay KL, Kidd GJ, Miller RH, Trapp BD. NG2-positive cells generate A2B5-positive oligodendrocyte precursor cells. GLIA. 2007 2007-08-01;55(10):1001-10.

35. Temple S, Raff MC. Clonal analysis of oligodendrocyte development in culture: evidence for a developmental clock that counts cell divisions. CELL. 1986 1986-03-14;44(5):773-9.

36. Barateiro A, Fernandes A. Temporal oligodendrocyte lineage progression: in vitro models of proliferation, differentiation and myelination. Biochim Biophys Acta. 2014 2014-09-01;1843(9):1917-29. 


\section{Figures}
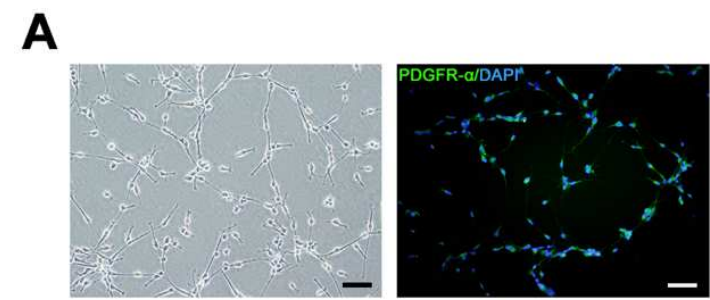

B
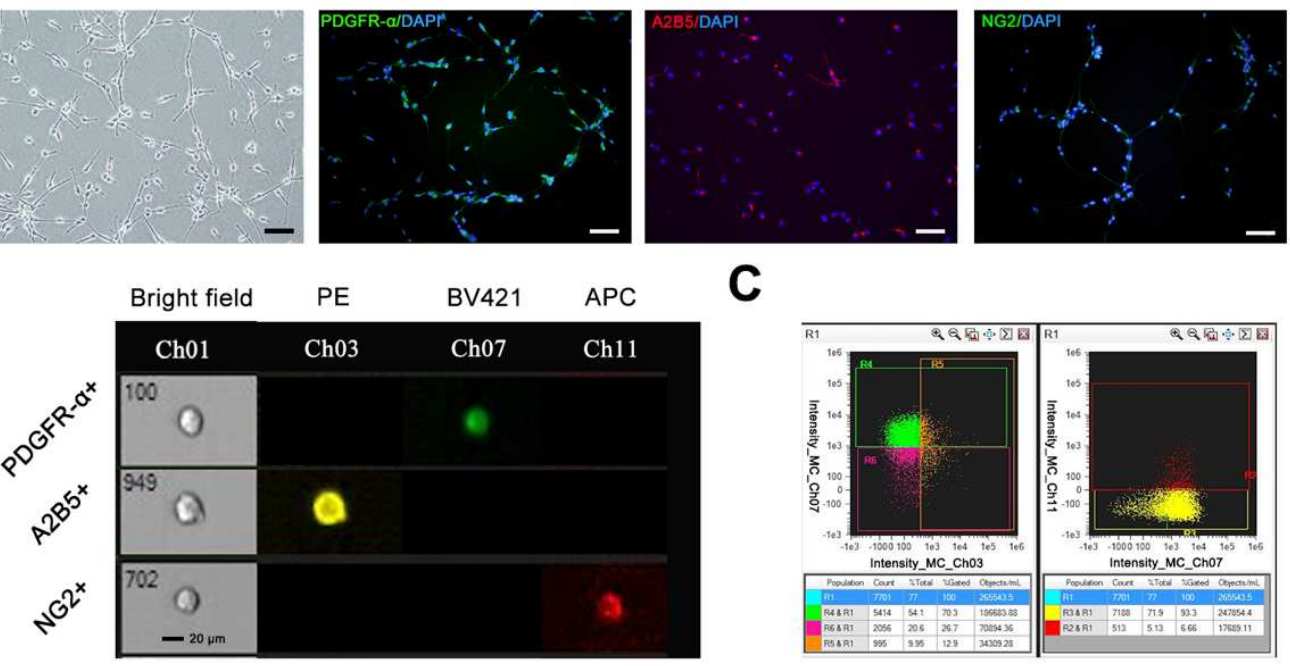

C

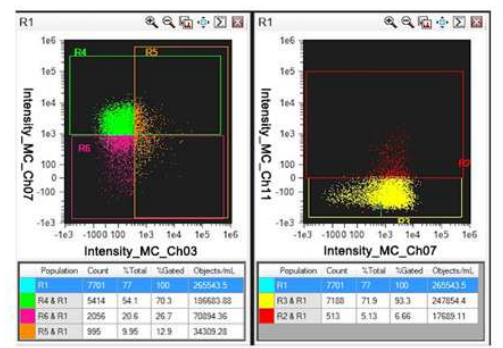

D
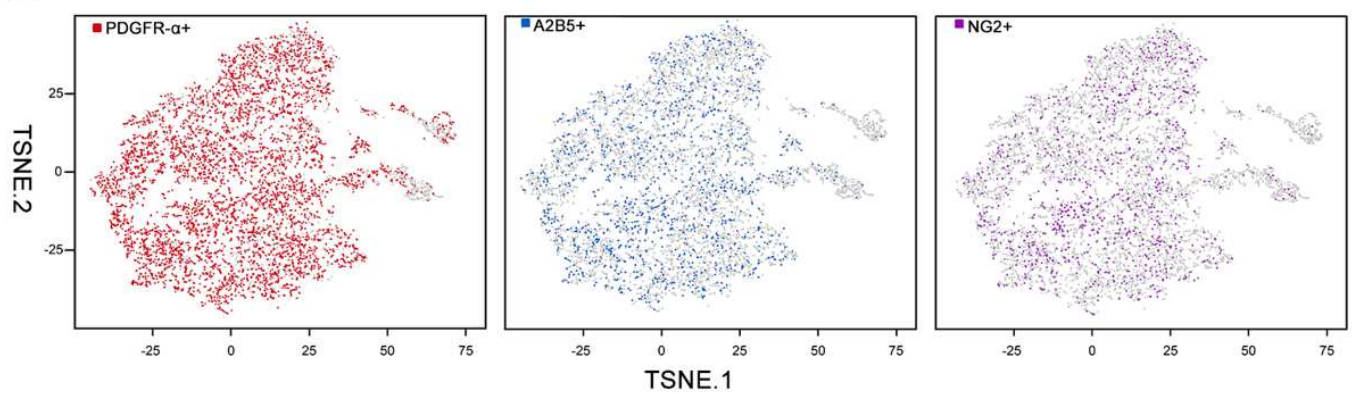

Figure 1 - Identification of hOPC markers

A Three markers of hOPCs were identified using cell immunofluorescence staining: PDGFR- $\alpha$, A2B5, and NG2. Scale bar is $200 \mu \mathrm{m}$.

B Images of single cells detached in the presence of PDGFR- $\alpha+$, A2B5+, and NG2+ cells, as observed using flow cytometry. Ch01: Bright field, Ch03: A2B5-PE, Ch07: PDGFR- $\alpha-B V 421$, Ch11: NG2-APC. Scale bar is $20 \mu \mathrm{m}$.

C Gating strategy to define PDGFR- $\alpha /$ A2B5/NG2 cells. R4: PDGFR- $\alpha+$ cells, R5: A2B5+ cells, R2: NG2+ cells.

D scRNA-seq of hOPCs. Maps of t-SNE of 7885 cells from high-dimensional images of hOPCs coloured according to the cell-type.

hOPC, human oligodendrocyte progenitor cells; PDGFR- $\alpha$, platelet derived growth factor receptor alpha; scRNA-seq, single cell RNA sequencing 
A
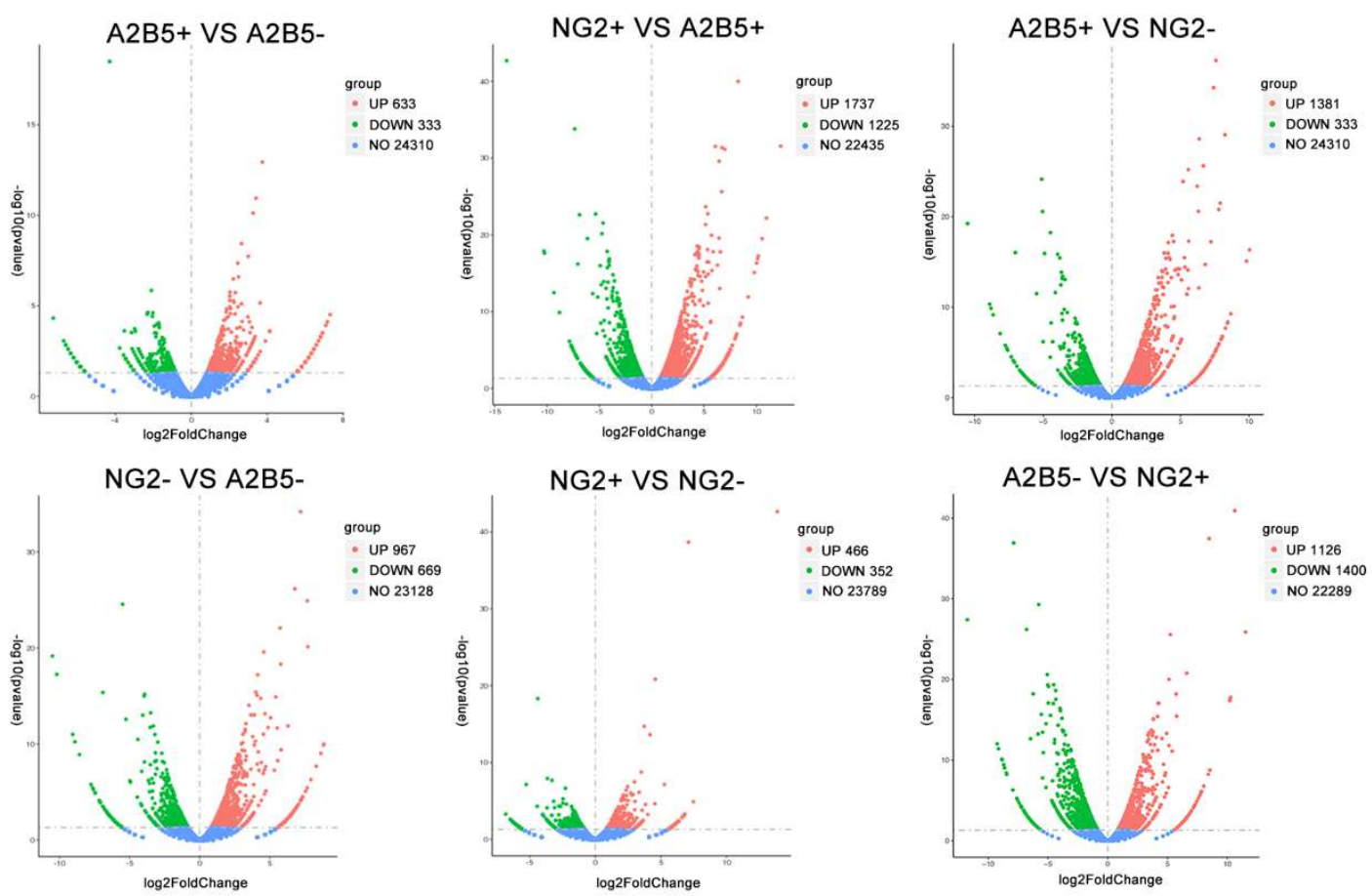

B

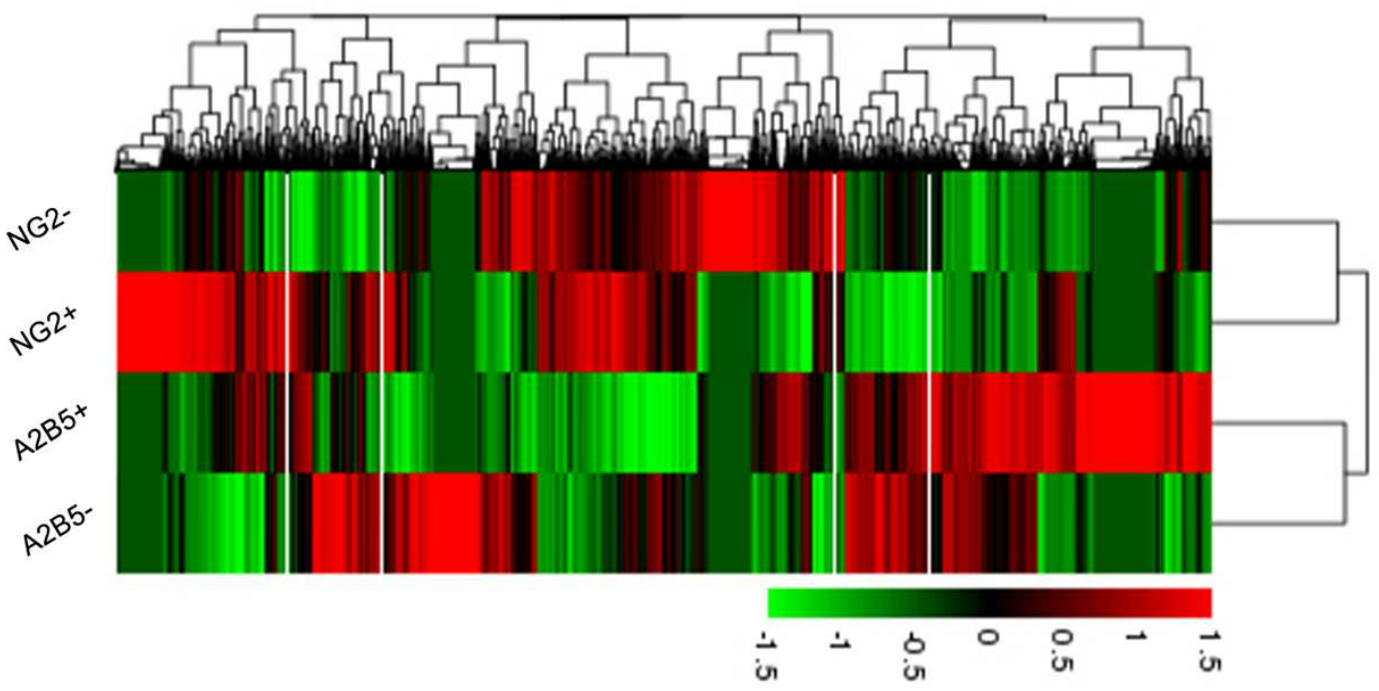

Figure 2 - Differential expression analysis

A Volcano plot illustrating differentially regulated gene expression between the four groups of cells. Red dots indicate upregulated genes, and blue dots indicate downregulated genes. Values are presented as the $\log 2$ of tag counts.

B Heat map showing the relative gene expression in NG2+/- and A2B5+/- cells. Red and green indicate upregulated and downregulated genes, respectively. 
A

\begin{tabular}{|c|c|c|}
\hline Category & GOID & Description \\
\hline $\mathrm{BP}$ & GO:0021953 & central nervous system neuron differentiation \\
\hline $\mathrm{BP}$ & GO:0010001 & glial cell differentiation \\
\hline $\mathrm{BP}$ & GO:0061564 & axon development \\
\hline $\mathrm{BP}$ & GO:0042063 & gliogenesis \\
\hline$B P$ & GO:0007409 & axonogenesis \\
\hline $\mathrm{BP}$ & GO:0048709 & oligodendrocyte differentiation \\
\hline $\mathrm{BP}$ & GO:0001764 & neuron migration \\
\hline $\mathrm{BP}$ & GO:0014003 & oligodendrocyte development \\
\hline $\mathrm{BP}$ & GO:0007411 & axon guidance \\
\hline $\mathrm{BP}$ & GO:0051962 & positive regulation of nervous system development \\
\hline $\mathrm{BP}$ & GO:0045687 & positive regulation of glial cell differentiation \\
\hline $\mathrm{BP}$ & GO:0045685 & regulation of glial cell differentiation \\
\hline $\mathrm{BP}$ & GO:0007422 & peripheral nervous system development \\
\hline $\mathrm{BP}$ & GO:0007219 & Notch signaling pathway \\
\hline $\mathrm{BP}$ & GO:0045747 & positive regulation of Notch signaling pathway \\
\hline $\mathrm{BP}$ & GO:0045666 & positive regulation of neuron differentiation \\
\hline $\mathrm{BP}$ & GO:0050673 & epithelial cell proliferation \\
\hline $\mathrm{BP}$ & GO:0022010 & central nervous system myelination \\
\hline $\mathrm{BP}$ & GO:0032291 & axon ensheathment in central nervous system \\
\hline $\mathrm{BP}$ & GO:0048714 & positive regulation of oligodendrocyte differentiation \\
\hline $\mathrm{BP}$ & GO:0021675 & nerve development \\
\hline $\mathrm{BP}$ & GO:0042552 & myelination \\
\hline $\mathrm{BP}$ & GO:0008366 & axon ensheathment \\
\hline $\mathrm{BP}$ & GO:0021846 & cell proliferation in forebrain \\
\hline$B P$ & GO:0050679 & positive regulation of epithelial cell proliferation \\
\hline $\mathrm{BP}$ & GO:0014909 & smooth muscle cell migration \\
\hline $\mathrm{BP}$ & GO:0014812 & muscle cell migration \\
\hline $\mathrm{BP}$ & GO:0048144 & fibroblast proliferation \\
\hline $\mathrm{BP}$ & GO:0050900 & leukocyte migration \\
\hline $\mathrm{BP}$ & GO:0001935 & endothelial cell proliferation \\
\hline $\mathrm{CC}$ & G0:0150034 & distal axon \\
\hline $\mathrm{CC}$ & GO:0005578 & proteinaceous extracellular matrix \\
\hline $\mathrm{CC}$ & GO:0033267 & axon part \\
\hline $\mathrm{CC}$ & GO:0030673 & axolemma \\
\hline $\mathrm{CC}$ & GO:0031012 & extracellular matrix \\
\hline MF & GO:0003779 & actin binding \\
\hline
\end{tabular}

B
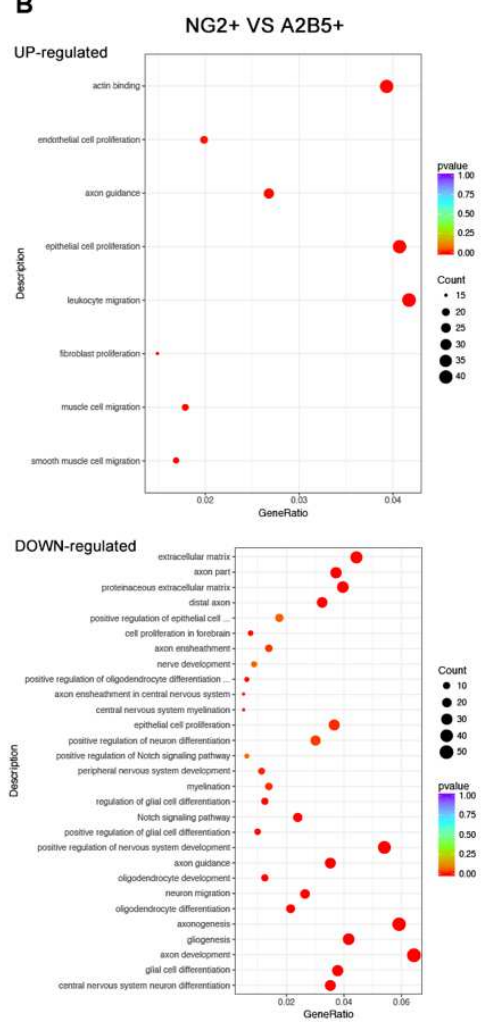

\section{Figure 3 - GO enrichment analysis}

A Table with specific instances of BP, CC, and MF.

B Bubble plots of the main enriched GO terms ( $\mathrm{NG} 2+$ vs A2B5+) for the upregulated and downregulated genes.

GO, gene ontology 

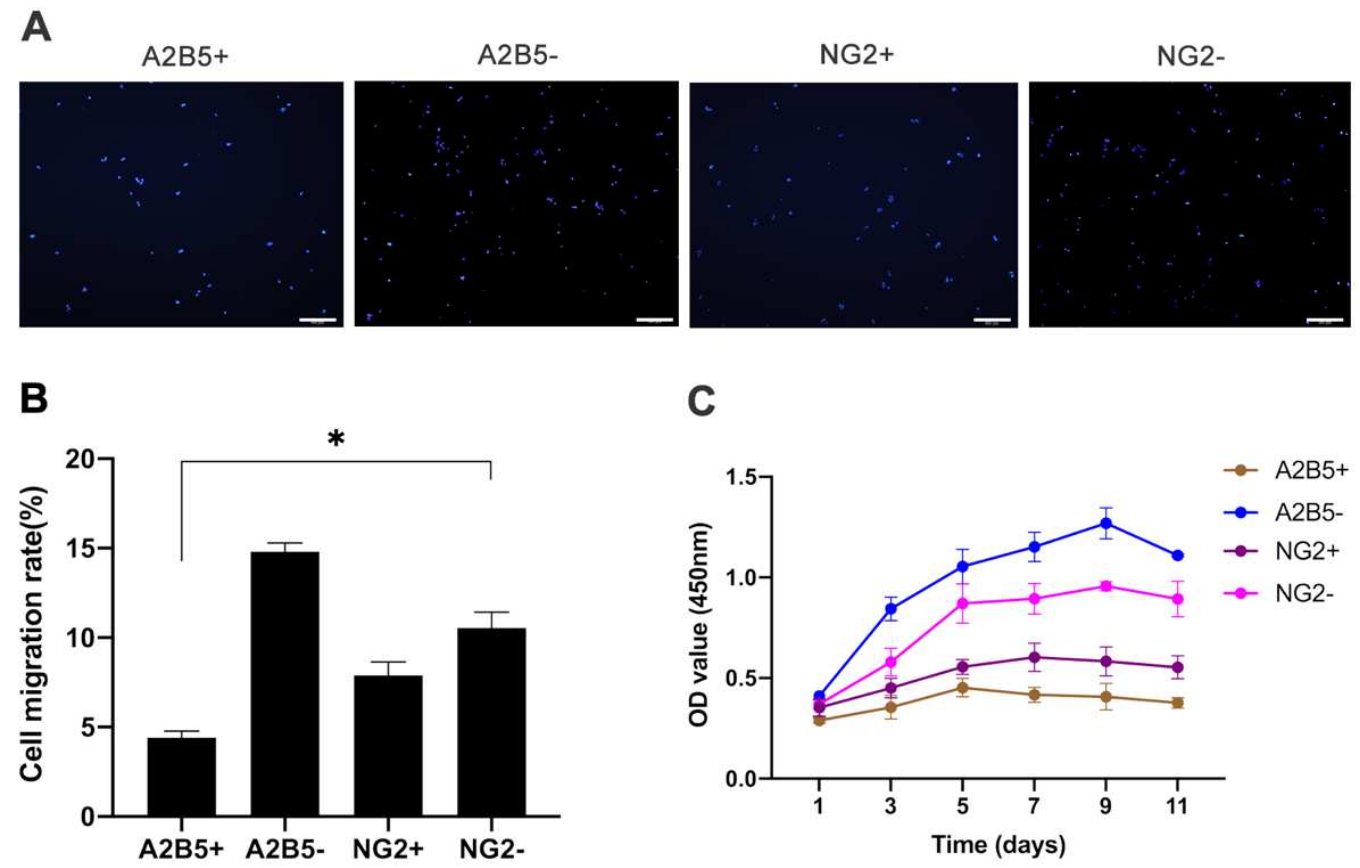

Figure 4 - Evaluation of the in vitro migration and proliferation function of hOPCs

A Migration assay. Microscopic images show DAPI staining of migrating cell nuclei. Scale bar is $200 \mu \mathrm{m}$.

B Graph showing the cell migration rate. Bars represents means. Error bars show the standard error of the mean.

C CCK-8 cell proliferation assay after $1,3,5,7,9$, and 11 days. hOPC, human oligodendrocyte progenitor cells, CCK, cell-counting kit. 
A
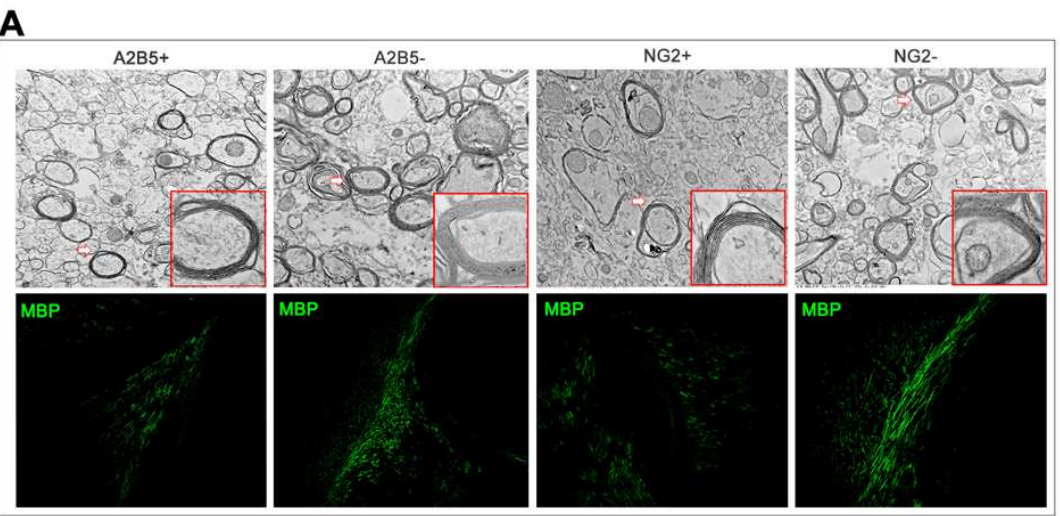

B

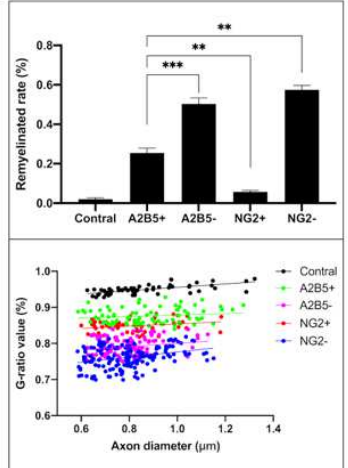

Figure 5 - TEM and immunohistochemical analysis

A Electron micrographs showing a sagittal section through the corpus callosum of shiverer mice. Magnification: 20000X; inset 60000X. Alexa 488-labelled abundant, donor-derived MBP (green) of four transplanted cells. Scale bar is $200 \mu \mathrm{m}$.

B Graph showing the remyelination rate of different groups and plot showing the G-ratios. Bars represent means. Error bars show the standard error of the mean.

TEM, transmission electron microscopy; MBP, myelin basic protein 


\section{Figures}

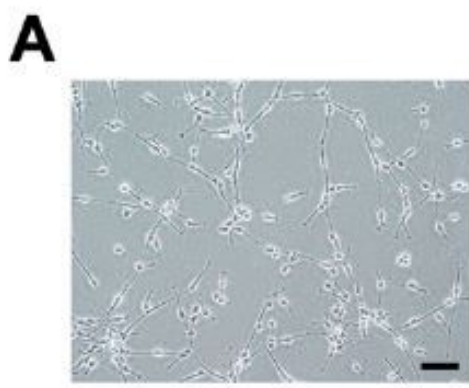

B

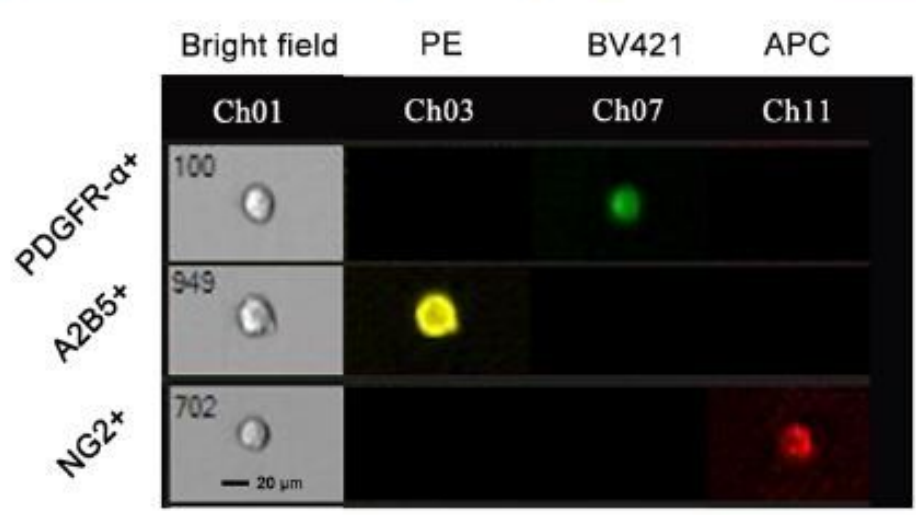

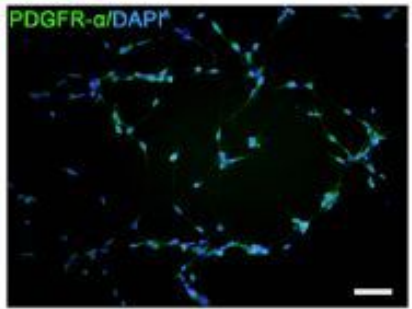
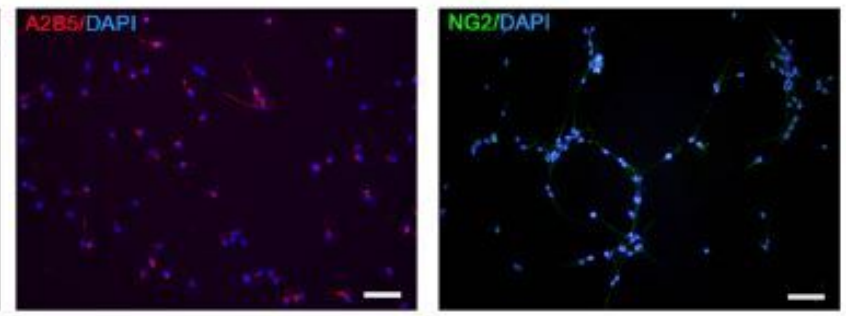

C

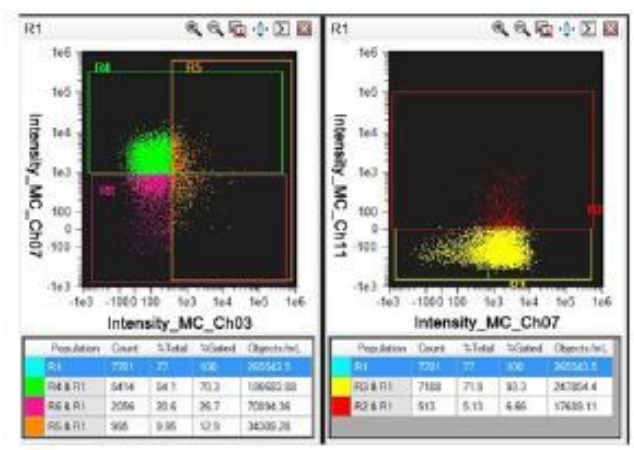

D
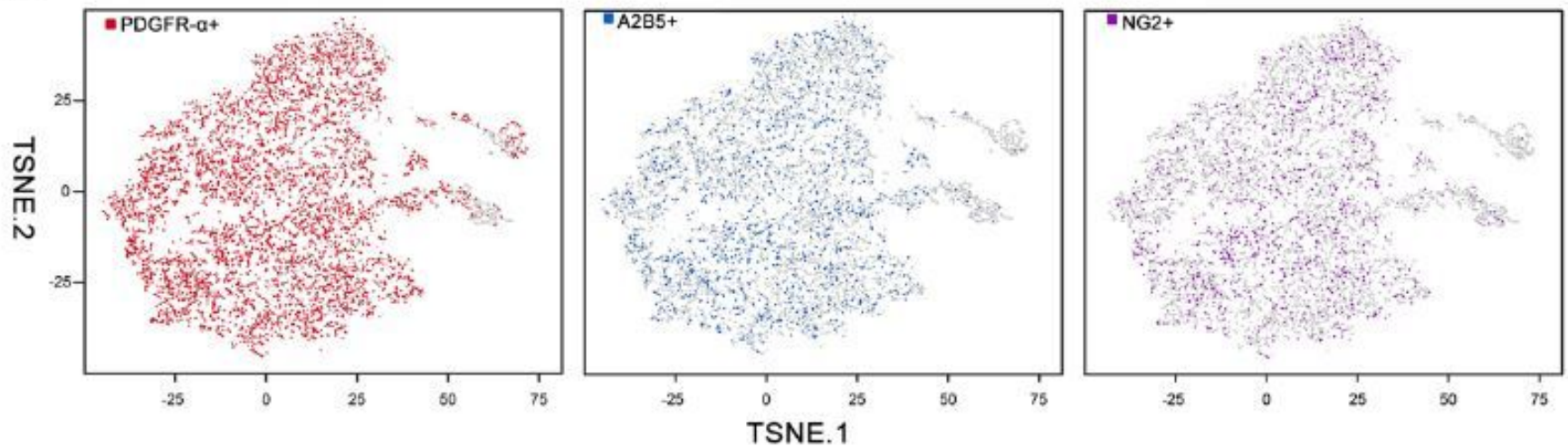

TSNE. 1

\section{Figure 1}

Identification of hOPC markers A Three markers of hOPCs were identified using cell immunofluorescence staining: PDGFR-a, A2B5, and NG2. Scale bar is $200 \mu \mathrm{m}$. B Images of single cells detached in the presence of PDGFR-a+, A2B5+, and NG2+ cells, as observed using flow cytometry. Ch01: Bright field, Ch03: A2B5-PE, Ch07: PDGFR-a-BV421, Ch11: NG2-APC. Scale bar is $20 \mu \mathrm{m}$. C Gating strategy to define PDGFR-a/A2B5/NG2 cells. R4: PDGFR-a+ cells, R5: A2B5+ cells, R2: NG2+ cells. D scRNA-seq of hOPCs. Maps of t-SNE of 7885 cells from high-dimensional images of hOPCs coloured according to the cell-type. hOPC, human oligodendrocyte progenitor cells; PDGFR-a, platelet derived growth factor receptor alpha; scRNA-seq, single cell RNA sequencing 
A
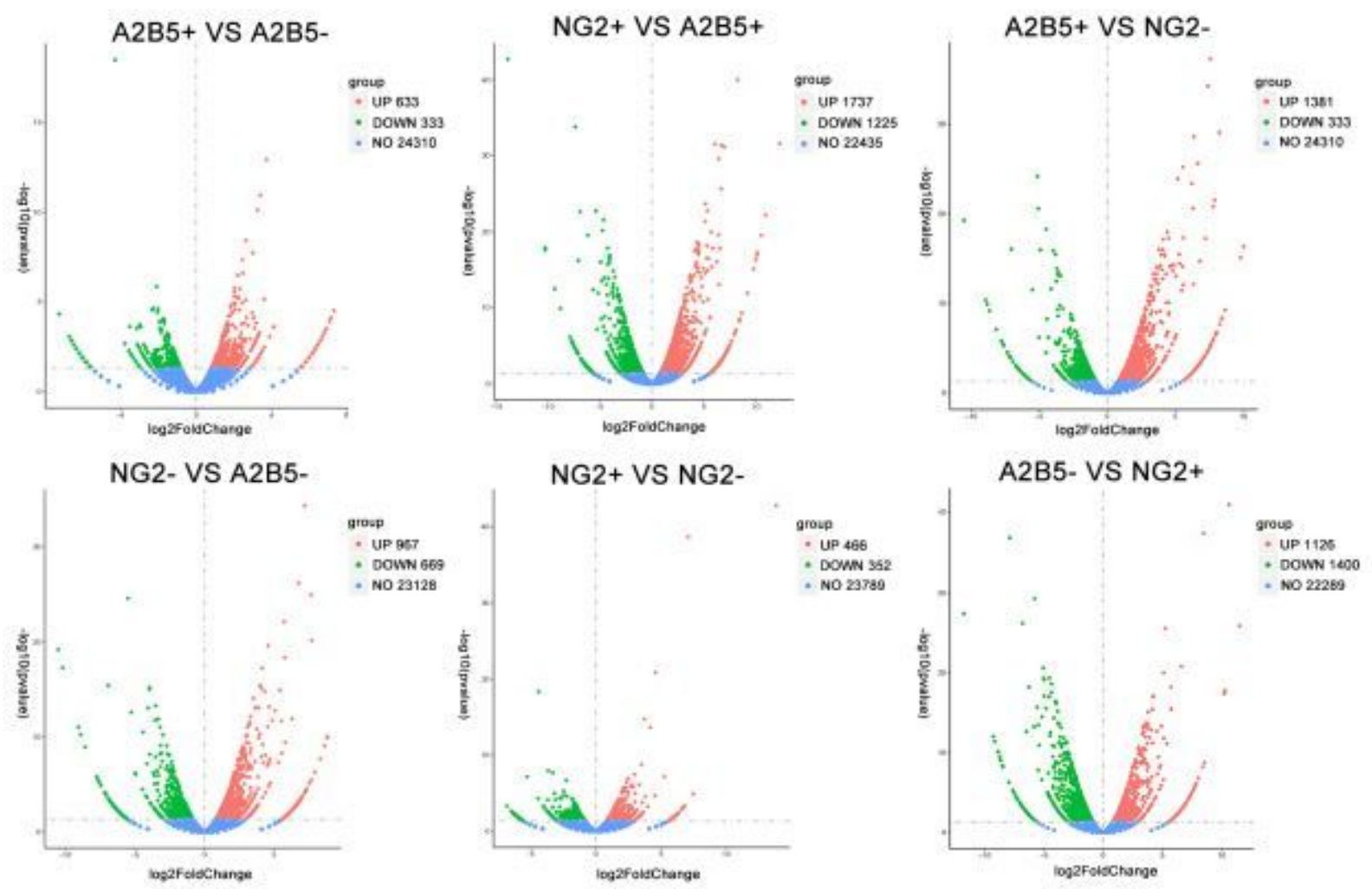

B

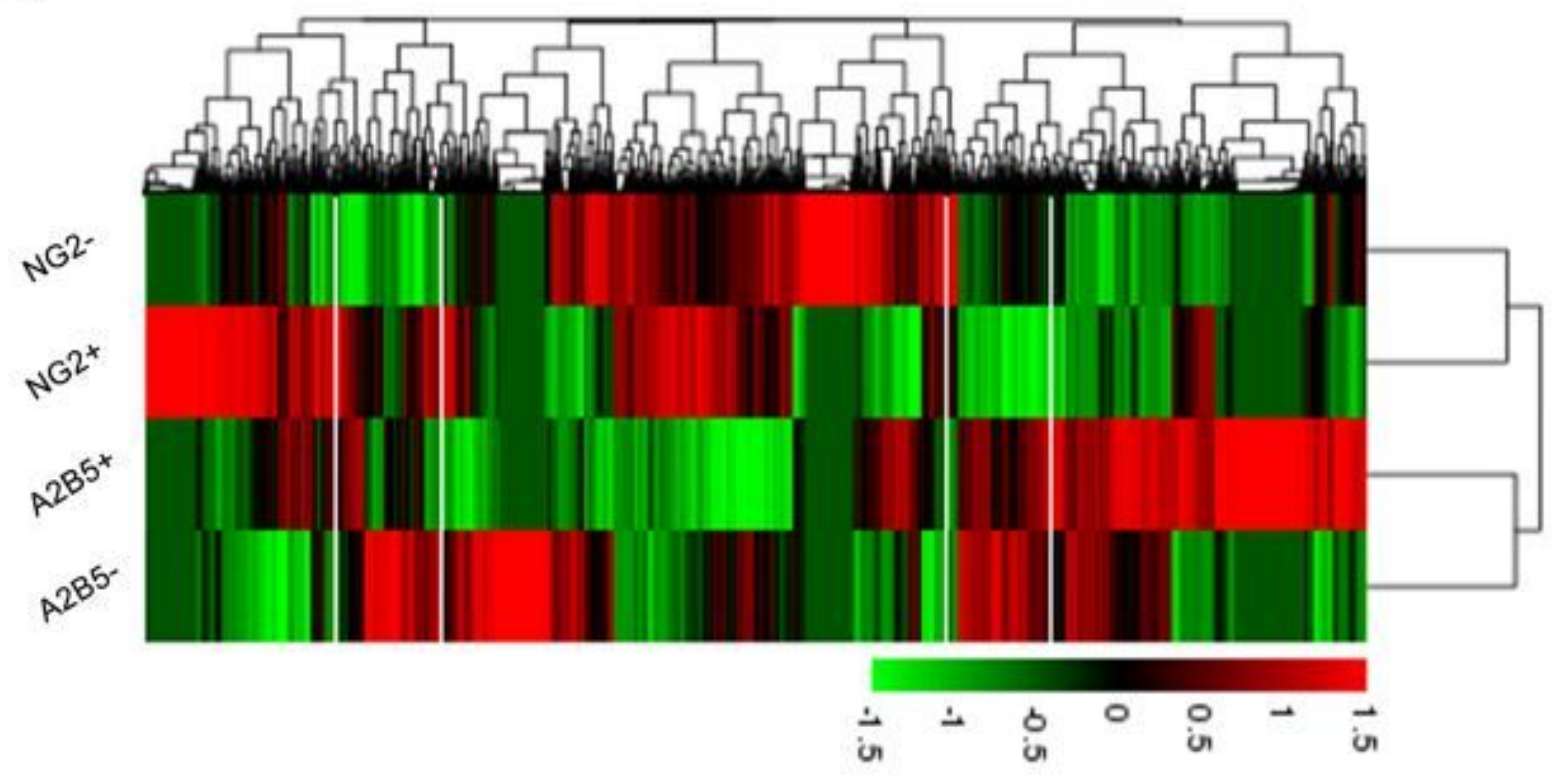

\section{Figure 2}

Differential expression analysis A Volcano plot illustrating differentially regulated gene expression between the four groups of cells. Red dots indicate upregulated genes, and blue dots indicate downregulated genes. Values are presented as the log2 of tag counts. B Heat map showing the relative gene expression in $\mathrm{NG} 2+/-$ and $\mathrm{A} 2 \mathrm{~B} 5+/$ - cells. Red and green indicate upregulated and downregulated genes, respectively. 
A

\begin{tabular}{|c|c|c|}
\hline Category & GOID & Description \\
\hline $\mathrm{BP}$ & GO-0021953 & central nervous system neuron differentiation \\
\hline $\mathrm{BP}$ & G0:0010001 & glial cell differentiation \\
\hline$B P$ & GO:0061564 & axon development \\
\hline $\mathrm{BP}$ & GO:0042063 & gliogenesis \\
\hline$\overline{B P}$ & GO:0007409 & axonogenesis \\
\hline $\mathrm{BP}$ & 60:0048709 & oligodendrocyte differentiation \\
\hline $\mathrm{BP}$ & GO:0001764 & neuron migration \\
\hline $\mathrm{BP}$ & 60:0014003 & oligodendrocyte development \\
\hline $\mathrm{BP}$ & GO:0007411 & axon guidance \\
\hline $\mathrm{BP}$ & GO:0051962 & positive regulation of nervous system development \\
\hline $\mathrm{BP}$ & GO:0045687 & positive regulation of glial cell differentiation \\
\hline $\mathrm{BP}$ & GO:0045685 & regulation of glial cell differentiation \\
\hline $\mathrm{BP}$ & GO:0007422 & peripheral nervous system development \\
\hline $\mathrm{BP}$ & GO:0007219 & Notch signaling pathway \\
\hline $\mathrm{BP}$ & GO:0045747 & positive regulation of Notch signaling pathway \\
\hline $\mathrm{BP}$ & GO:0045666 & positive regulation of neuron differentiation \\
\hline $\mathrm{BP}$ & GO:0050673 & epithelial cell proliferation \\
\hline $\mathrm{BP}$ & 60:0022010 & central nervous system myelination \\
\hline $\mathrm{BP}$ & GO:0032291 & axon ensheathment in central nervous system \\
\hline $\mathrm{BP}$ & 60:0048714 & positive regulation of oligodendrocyte differentiation \\
\hline $\mathrm{BP}$ & GO:0021675 & nerve development \\
\hline $\mathrm{BP}$ & GO:0042552 & myelination \\
\hline $\mathrm{BP}$ & G0:0008366 & axon ensheathment \\
\hline $\mathrm{BP}$ & G0:0021846 & cell proliferation in forebrain \\
\hline $\mathrm{BP}$ & GO:0050679 & positive regulation of epithelial cell proliferation \\
\hline $\mathrm{BP}$ & 60:0014909 & smooth muscle cell migration \\
\hline $\mathrm{BP}$ & GO:0014812 & muscle cell migration \\
\hline $\mathrm{BP}$ & GO:0048144 & fibroblast proliferation \\
\hline $\mathrm{BP}$ & GO:0050900 & leukocyte migration \\
\hline $\mathrm{BP}$ & GO:0001935 & endothelial cell proliferation \\
\hline $\mathrm{CC}$ & GO 0150034 & distal axon \\
\hline $\mathrm{CC}$ & 60:0005578 & proteinaceous extracellular matrix \\
\hline $\mathrm{CC}$ & 60:0033267 & axon part \\
\hline $\mathrm{CC}$ & $60: 0030673$ & axolemma \\
\hline $\mathrm{CC}$ & G0:0031012 & extracellular matrix \\
\hline MF & GO:0003779 & actin binding \\
\hline
\end{tabular}

B
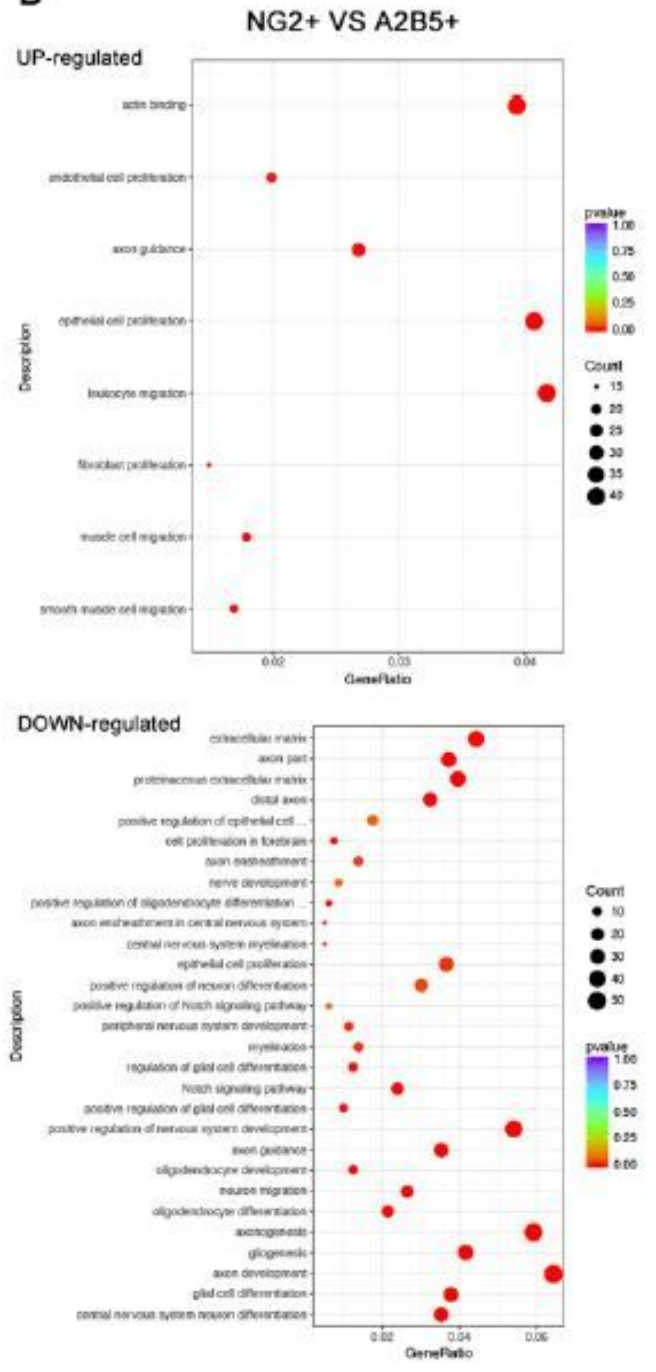

Figure 3

GO enrichment analysis A Table with specific instances of BP, CC, and MF. B Bubble plots of the main enriched GO terms (NG2+ vs A2B5+) for the upregulated and downregulated genes. GO, gene ontology 
A

A2B5+

A2B5-

NG2+

NG2-
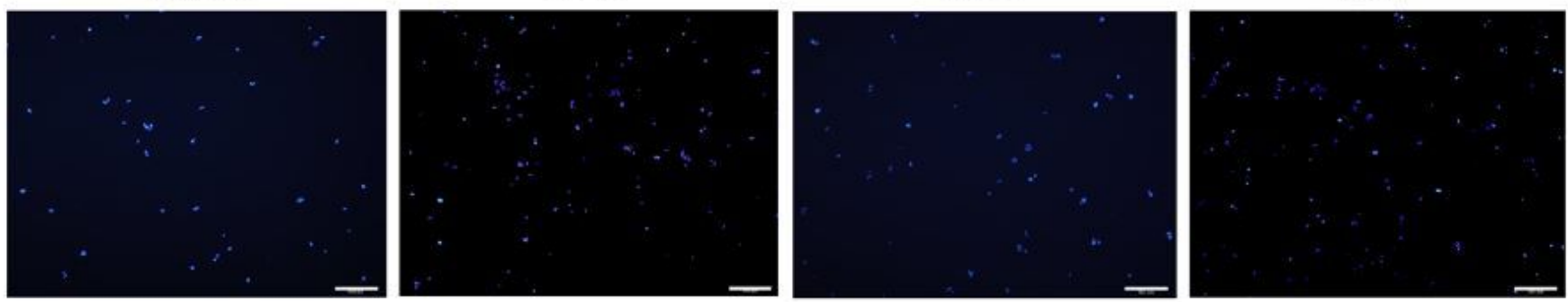

B

C
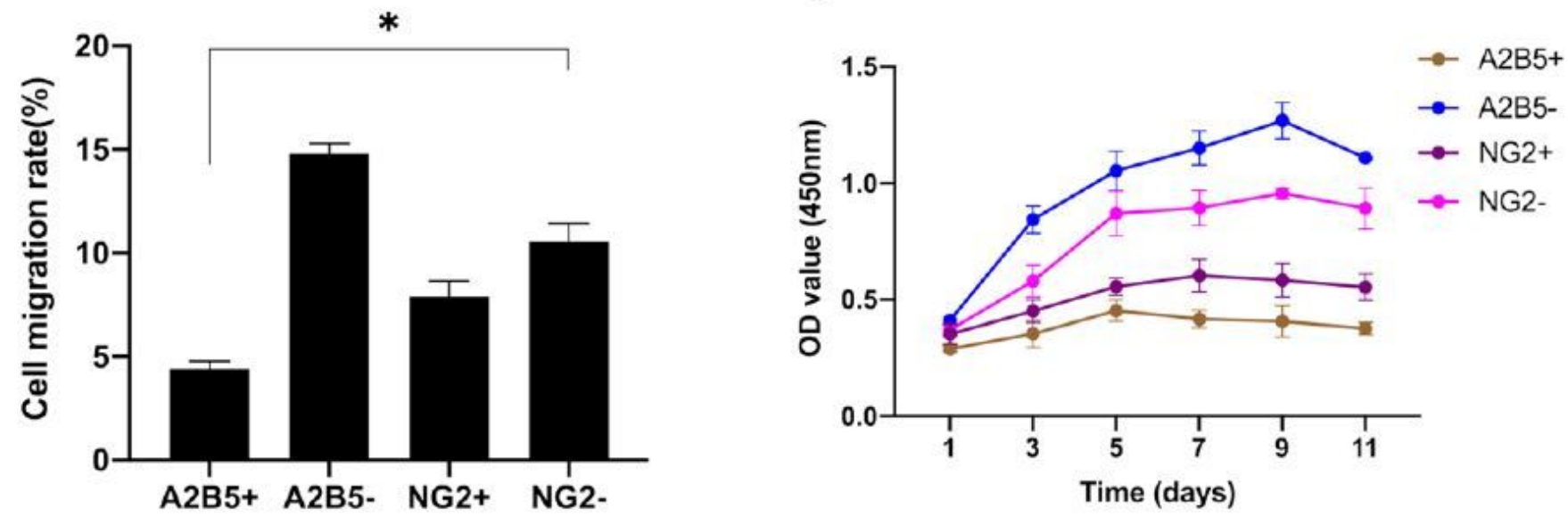

Figure 4

Evaluation of the in vitro migration and proliferation function of hOPCs A Migration assay. Microscopic images show DAPI staining of migrating cell nuclei. Scale bar is $200 \mu \mathrm{m}$. B Graph showing the cell migration rate. Bars represents means. Error bars show the standard error of the mean. C CCK-8 cell proliferation assay after $1,3,5,7,9$, and 11 days. hOPC, human oligodendrocyte progenitor cells, CCK, cell-counting kit.

A

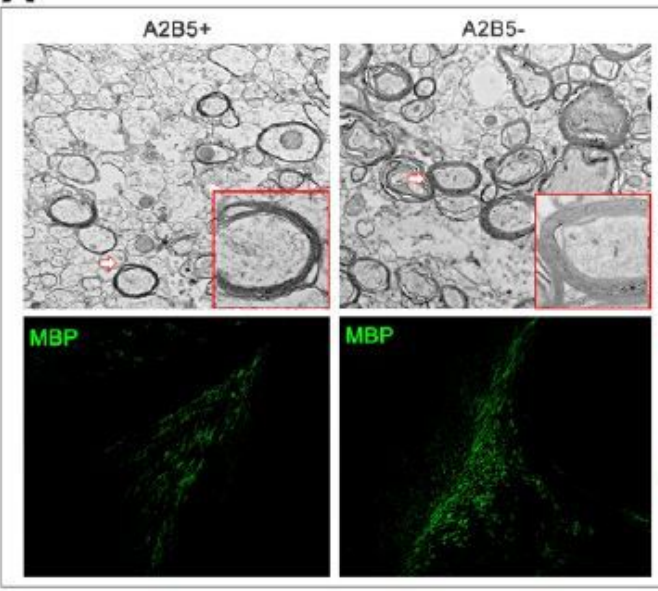

B

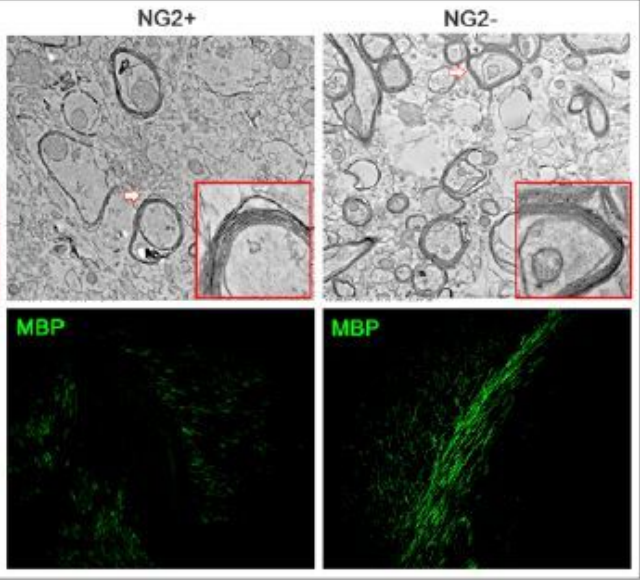

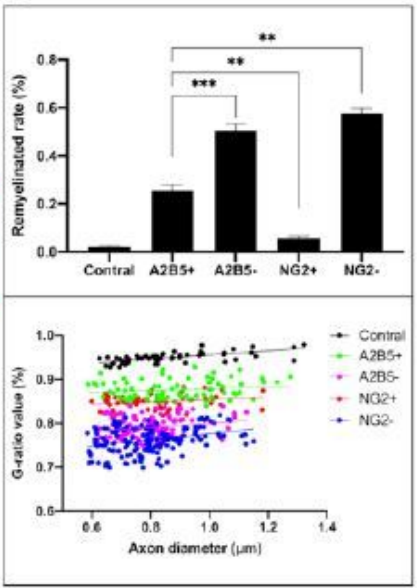




\section{Figure 5}

TEM and immunohistochemical analysis A Electron micrographs showing a sagittal section through the corpus callosum of shiverer mice. Magnification: 20000X; inset 60000X. Alexa 488-labelled abundant, donor-derived MBP (green) of four transplanted cells. Scale bar is $200 \mu \mathrm{m}$. B Graph showing the remyelination rate of different groups and plot showing the G-ratios. Bars represent means. Error bars show the standard error of the mean. TEM, transmission electron microscopy; MBP, myelin basic protein

\section{Supplementary Files}

This is a list of supplementary files associated with this preprint. Click to download.

- Supplementaryfile.pdf 